\title{
Communication \\ Hybrid Biomimetic Materials from Silica/Carbonate Biomorphs
}

\author{
Julian Opel ${ }^{1,2}$, Niklas Unglaube ${ }^{1}$, Melissa Wörner ${ }^{1}$, Matthias Kellermeier ${ }^{3}$, \\ Helmut Cölfen 1,*(D) and Juan-Manuel García-Ruiz ${ }^{2, *}$ \\ 1 Physical Chemistry, University of Konstanz, Universitätsstrasse 10, D-78457 Konstanz, Germany; \\ julian.opel@uni-konstanz.de (J.O.); niklas.unglaube@uni.kn (N.U.); melissa.woerner@uni.kn (M.W.) \\ 2 Laboratorio de Estudios Cristalográficos, Instituto Andaluz de Ciencias de la Tierra (CSIC-UGR), \\ Avenida de las Palmeras 4, E-18100 Armilla, Granada, Spain \\ 3 Material Physics, BASF SE, RAA/OS-B007, Carl-Bosch-Strasse 38, D-67056 Ludwigshafen, Germany; \\ matthias.kellermeier@basf.com \\ * Correspondence: helmut.coelfen@uni-konstanz.de (H.C.); jmgruiz@ugr.es (J.-M.G.-R.); \\ Tel.: +49-7531-884063 (H.C.); +34-669434700 (J.-M.G.-R.)
}

Received: 28 February 2019; Accepted: 14 March 2019; Published: 18 March 2019

\begin{abstract}
The formation of a polymer protection layer around fragile mineral architectures ensures that structures stay intact even after treatments that would normally destroy them going along with a total loss of textural information. Here we present a strategy to preserve the shape of silica-carbonate biomorphs with polymers. This method converts non-hybrid inorganic-inorganic composite materials such a silica/carbonate biomorphs into hybrid organic/carbonate composite materials similar to biominerals.
\end{abstract}

Keywords: biomorphs; barium carbonate; silica; PCDA; pyrrole

\section{Introduction}

Silica-earth-alkaline carbonate composites show exceptional shapes which is so far a one-of-a-kind appearance within the field of pure inorganic composites [1,2]. They were named silica-biomorphs due to their morphology, which resembles primitive living organisms and their inner textures mimic biominerals [3]. Compared to biominerals, which are normally hierarchically ordered hybrid composites consisting of inorganic minerals and structure conducting organic matter [4-6], biomorphs are purely inorganic composite materials, the structuring role of organic compounds being taken over by amorphous silica. They are self-organized structures that forms upon the coupled co-precipitation of silica $\left(\mathrm{SiO}_{2}\right)$ and alkaline -earth metal carbonates, namely witherite $\left(\mathrm{BaCO}_{3}\right)$, strontianite $(\mathrm{SrCO})$ or either aragonite or monohydrocalcite $\left(\mathrm{CaCO}_{3}\right)$ [7-10]. The formation of biomorphs can be described in three stages which are related to $\mathrm{pH}$ [11]. In the first stage, the initial single crystal of alkaline -earth metal carbonate experiences splitting provoked by selective adsorption of silica. Iterative splitting triggers fractal growth and eventually leads to primary globular particles [12-14]. The precipitation of the carbonate induces a local and bulk decrease of the $\mathrm{pH}$ that can be monitored even at this very early stage $[11,15,16]$. At this stage nearly no silica is adsorbed within the structure [11]. The second stage starts after some time (depending on the initial $\mathrm{pH}$ ) and more complex structures form by determining the final shape of the biomorph. During this stage a polycrystalline growth of a myriad of elongated witherite nanorods with a typical size of 200-400 nm in length and 30-50 nm in thickness can be observed [11]. Once the $\mathrm{pH}$ drops far enough, the biomorph formation enters the last stage where only secondary precipitation processes occur. Due to the inverse solubility of silica with respect to $\mathrm{pH}[17,18]$, the structures become embedded in a thick silica shell, which grows bigger if the structures mature in the mother solution. 
Once extracted from the mother solution, the biomorphs can be further treated as shown in Figure 1. The composite is hollowed by acidic treatment. A diluted hydrochloric or acetic acid can be used to dissolve the inner part within minutes [19]. The result is a hollow structure, which is called a biomorph "ghost." Alternatively, an alkaline treatment with sodium hydroxide solution allows the removal of the silica shell and excavates the so-called "naked" biomorph (cf. Figure 1) [20]. A naked biomorph is useful for attachment of molecules or particles with carboxylate groups. One example for an attachment of a monomeric carboxylate species is 10,12-pentacosadiynoic acid (PCDA), a light-polymerizable diacetylen [20]. Poly-PCDA (pPCDA), as a member of the polydiacetylene family, comes with thermochromic properties and can be reversibly or irreversibly switched from a blue into a red state $[21,22]$. Besides PCDA, conductive polymers like polypyrrole (pPy) or poly thiophenes generated a growing interest in the field of biomineral preservation and replication [23-25]. Furthermore they provide some additional functionality and are used as chemical sensors [26,27], in drug delivery [27], as electronic devices like fuel cells [28] or electro-catalysts [29] and in combination with silica for chromatographic applications [30]. Choi et al. presented hierarchically structured pPy in helicoidal shapes and consequently, a pPy replica of a biomorph helix should also be usable as stretchable supercapacitors [31].

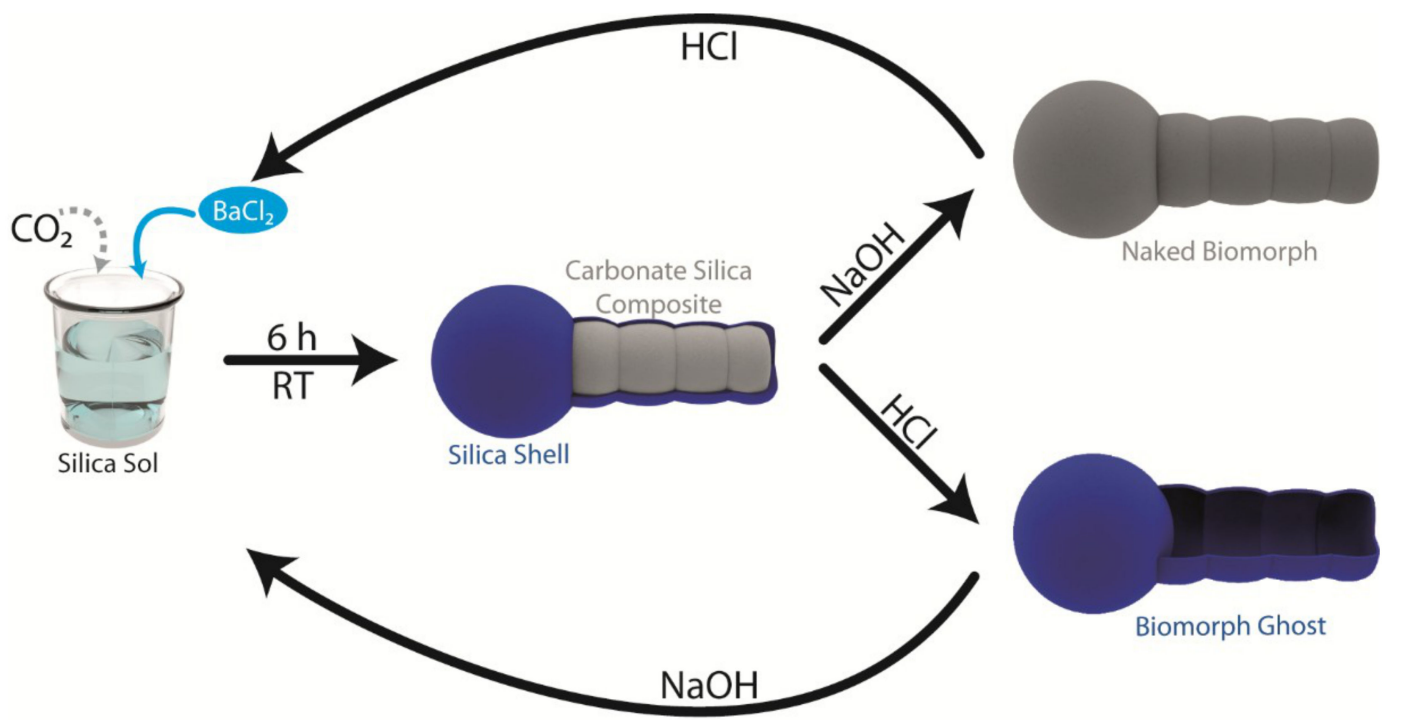

Figure 1. Schematic illustration of biomorph formation at room temperature (RT) and pathways to dissolve each part of composite selectively and return to its precursor state. As intermediate a naked biomorph with an excavated carbonate surface or a hollow biomorph ghost can be obtained.

So far, two known strategies exist to transfer hierarchical structures of a given material into a new one of different composition. The first method is to demineralize a biomineral to obtain an organic template and re-infiltrate the matrix with the new compound [32]. The second strategy consists of replacing the organic matrix with a new material, as shown by Imai and co-workers with dyes or polymers between nanocrystals [33,34]. We show here that a polymer layer around a biomorphic structure sustains the morphology after additional treatment with alkaline and/or acidic solutions while an unpreserved structure vanishes into its precursor state. In total, the following work demonstrates a successful preservation of micro-sculptures with two chosen straightforward pathways and elaborate a third strategy to transfer hierarchical structures into functional organic materials. 


\section{Materials and Methods}

Barium chloride dihydrate ( $>99 \%$ ), sodium hydroxide (reagent grade, $>98 \%$ ), sodium silicate solution (commercial water glass, containing $10.6 \% \mathrm{Na}_{2} \mathrm{O}$ and $26.5 \% \mathrm{SiO}_{2}$, reagent grade, density $1.39 \mathrm{~g} / \mathrm{ml}$ ), copper chloride (97\%), 10,12-pentacosadiynoic acid (>97\%) and pyrrole (reagent grade, 98\%) were purchased from Sigma-Aldrich and used without further purification. Aqueous solutions were prepared using MilliQ water with a conductivity of $18 \mu \mathrm{S} / \mathrm{cm}$.

\subsection{Biomorph Formation}

Silica-biomorphs were grown from alkaline silica sol which was prepared by $1.39 \mathrm{~g}$ of silica solution diluted with $349 \mathrm{~mL}$ of water. The $\mathrm{pH}$ of the solution was adjusted to 11.3 with aliquots of $0.1 \mathrm{M} \mathrm{NaOH}$ solution. The crystallization occurs in a 6-wells linbro plate by mixing $4 \mathrm{~mL}$ of the silica solution with $4 \mathrm{~mL}$ of a $10 \mathrm{mM} \mathrm{BaCl} 2$ solution. After $8-16 \mathrm{~h}$ the structures were extracted from the wells and washed several times with water and ethanol $(\mathrm{EtOH})$. The outer silica layer was removed by incubating $20 \mathrm{mg}$ biomorph powder in $1 \mathrm{~mL}$ of a $1 \mathrm{M} \mathrm{NaOH}$ solution for $6 \mathrm{~h}$.

\section{2. pPCDA Functionalization}

PCDA solution was prepared by dissolving $50 \mathrm{mg}$ PCDA in $10 \mathrm{~mL}$ tetrahydrofuran (THF). The solution was filtered through a syringe filter (pore size: $0.22 \mu \mathrm{m}$ ) and diluted with $9 \mathrm{~mL}$ water and $1 \mathrm{~mL} 0.1 \mathrm{M} \mathrm{NaOH}$ solution. $10 \mathrm{mg}$ of naked biomorphs were incubated for $8 \mathrm{~h}$ inside a PCDA solution with different concentrations and stored in the dark. After extracting and washing, the structures can be stored under UV-light for 5 min inducing the polymerization to pPCDA. The colour of the biomorph PCDA powder changes to blue.

\section{3. pPy Functionalization}

$10 \mathrm{mg}$ naked biomorphs were added to $1 \mathrm{~mL}$ of a $0.01 \mathrm{M} \mathrm{CuCl}_{2}$ solution in isopropanol (iPrOH). After $1 \mathrm{~h}$, additional $750 \mu \mathrm{l}$ were added. After $1 \mathrm{~h}$ the structures were centrifuged and washed twice with $200 \mu$ iso-propanol (iPrOH). After drying the structures were stored in a desiccator containing $10 \mathrm{~mL}$ pyrrole. After $2 \mathrm{~h}$ the structures begin to darken and turned completely black after $6 \mathrm{~h}$. After the polymerization the inner core of the structures was removed with $0.05 \mathrm{M}$ acetic acid. The residue was washed several times with water and dried under reduced pressure.

\subsection{Analytical Methods}

The $\mathrm{pH}$ of the solutions was measured with a $\mathrm{pH}$ meter (Eutech $\mathrm{pH}$ 510, Eutech Instruments, Singapore). Scanning electron microscopy (SEM) images were recorded on a Hitachi Tabletop SEM TM3000 (Hitachi-Hightech, Krefeld, Germany) with a backscatter detector and a Zeiss Crossbeam 1540XB (Zeiss, Oberkochen, Germany) with a secondary electron (SE2) and an inlens detector. Energy dispersive X-ray spectroscopy (EDX) was also performed on the Hitachi TM3000. Light microscopy was performed on a Zeiss Imager $\mathrm{m} 2 \mathrm{~m}$ (Zeiss, Jena, Germany) and Axio Zoom (Zeiss, Jena, Germany). Confocal laser scanning microscopy (cLSM) was performed on a Zeiss LSM700 (Zeiss, Jena, Germany). Attenuated total reflection Fourier transformed infrared (ATR-FTIR) spectroscopy was performed on a Perkin Elmer Spectrum 100 (PerkinElmer, Waltham, MA, USA). 


\section{Results and Discussion}

\subsection{Preservation with $p P C D A$}

The first preservation route focuses on a light-polymerizable surfactant named PCDA. This molecule is immobilized on the witherite surface by incubating naked biomorphs (without an outer silica shell) in a mixture of sodium hydroxide, THF and water with different PCDA concentrations $(120-12,000 \mathrm{ppm})$. The attachment process is schematically shown in Figure 2A. To make sure that only the monomer is attached on the surface the solution was pushed through a syringe filter to remove polymer particles from the solution. The naked biomorphs were immersed in the colourless solution for several hours. To ensure that the PCDA does not polymerize during the attachment process, the samples were stored in darkness. After the chosen incubation time (4-16 h) the solution was removed and the modified biomorphs were dried under reduced pressure. The obtained modified structures were investigated with scanning electron microscopy (SEM). Observation of the structures with the electron beam induces polymerization of the attached monomers to the bluish pPCDA ( $c f$. inlet photos of the SEM stub before and after the SEM investigation in Figure 2B). To demonstrate the attachment of the PCDA on the structure, the process was observed by FTIR-spectroscopy. The transformation of the silica-biomorphs to the pPCDA-biomorphs is shown in Figure 2C. The black spectrum shows the characteristic carbonate (witherite) vibrations as well as the most abundant signal for amorphous silica (peak at $1000 \mathrm{~cm}^{-1}$ ). After treatment with $\mathrm{NaOH}$ and the transformation to the naked biomorphs, the broad peak vanishes and only the witherite signals remain (red spectrum). The modification with PCDA is observable as lines at 2870 and $2965 \mathrm{~cm}^{-1}$, which are the symmetric and asymmetric C-H vibrations. The carboxyl signal of the PCDA appears at $1540 \mathrm{~cm}^{-1}$ which is in good accordance to the literature [22]. Choosing a higher concentration of PCDA in the functionalization solution leads to the full coverage of the biomorph worm with pPCDA flakes, which preserve and display the outline of the structure beneath quite well. A detailed replica of the topography is not achievable with these high monomer concentrations. In previous work, we have demonstrated that the shape of the biomorph structure was preserved in acidic solutions even after removing the outer silica layer [20]. To ensure that a full coverage was achieved confocal laser scanning microscopy (cLSM) was used due to the strong fluorescence of pPCDA [20,35] (cf. Figure 2D,E). Smoothening the reprint might be possible by reducing the amount of monomer but a full coverage is not sustainable because an enrichment of PCDA was found inside of the notches of the biomorph worm ( $c f$. Figure $2 \mathrm{~F}, \mathrm{G}$ ). In Figure 2G at higher magnification the witherite nanorods and pPCDA flakes (false coloured in blue) can be visualized alongside each other. Excavated carbonate rods are not able to resist acidic solutions and therefore, the structures vanish completely after acid treatment. Also, the pPCDA flakes do not stick together and a polymer replica of the structures does not remain. The pPCDA coverage is useful to passivate bigger carbonate structures but a smooth and detailed replica cannot be obtained. Nevertheless, it still remains a readily applicable strategy to produce inverse biominerals. 


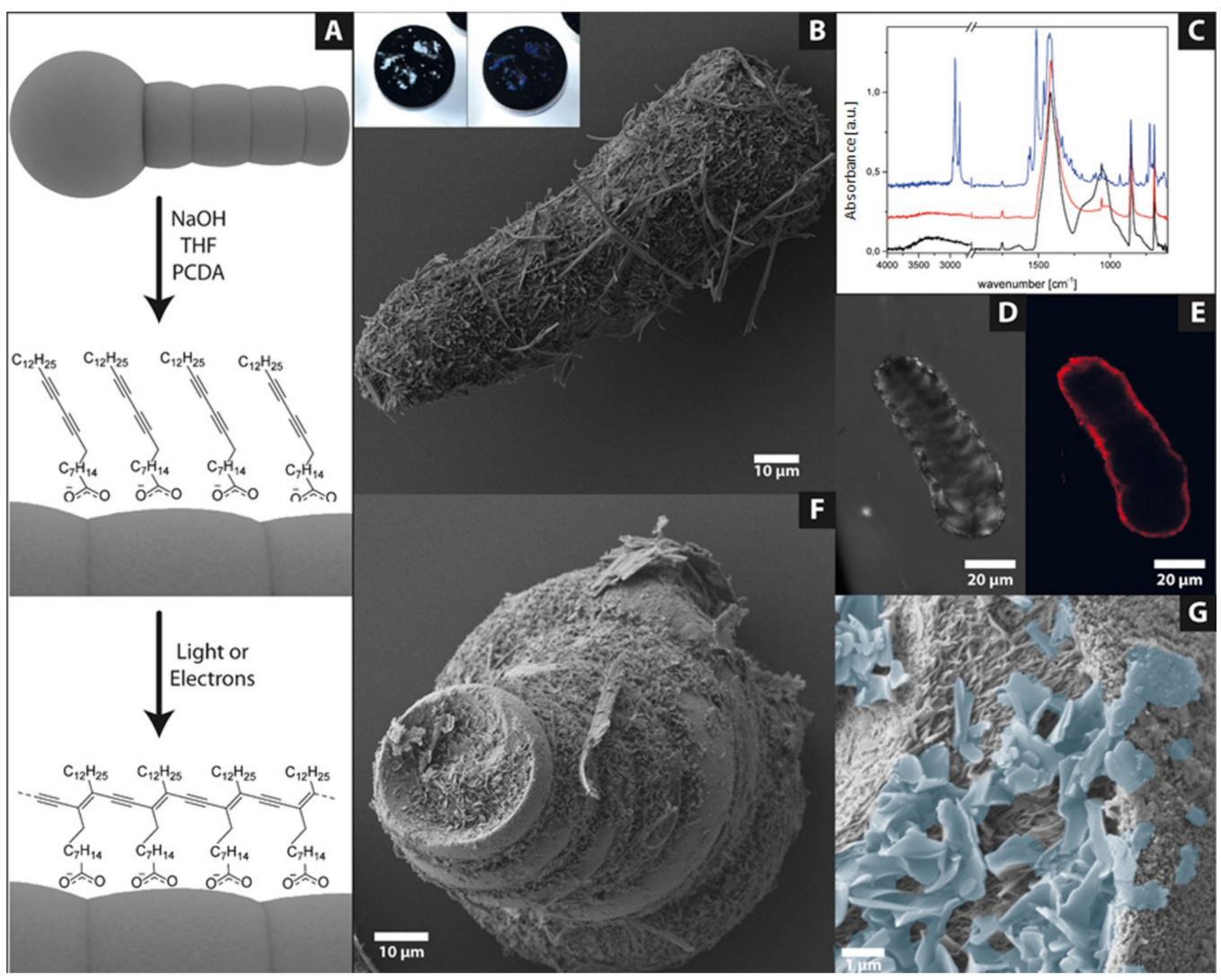

Figure 2. (A) Scheme of biomorph coverage with 10,12-pentacosadiynoic acid (PCDA) and the polymerization to PPCDA. (B) Scanning electron microscope (SEM) image of a fully covered biomorph worm (inlet: colour transformation of the powder after SEM investigation; $\mathrm{c}(\mathrm{PCDA})=12,000 \mathrm{ppm}$ ). (C) Attenuated total reflection Fourier transformed infrared (ATR-FTIR) spectra of an untreated biomorph (black) a naked biomorph (red) and a pPCDA covered biomorph (blue). (D/E) Confocal Laser scanning microscopy (cLSM) images of a fully covered biomorph worm in the transmission (D) and fluorescence (E) channel. (F) SEM image of a partially covered biomorph worm $(\mathrm{c}(\mathrm{PCDA})=2000 \mathrm{ppm})$ with the corresponding image at higher magnification (G), the blue coloured flakes indicate the PPCDA).

\subsection{Preservation with $p P y$}

Polypyrrole has gained attention due to its ability to produce polymer replicas of biominerals like sea urchin spines [25]. Recent breakthroughs in the preparation of polymer replicas on the micro scale are a huge improvement to preserve fragile structures and it now seems transferable to silica-biomorphs [23]. To obtain a full pPy coating around a biomorph we followed the route presented in Figure 3A. At first $\mathrm{CuCl}_{2}$ is brought onto the structure as a catalyst. Due to the rough surface of the naked biomorph, many small crystals of $\mathrm{CuCl}_{2}$ attach on the surface. These small crystals do not affect the shape as can be seen in Figure 3B. After drying, the structures were transferred into a desiccator. On the bottom of the desiccator, pyrrole was deposited creating a pyrrole saturated atmosphere. The pyrrole molecules diffuse to the catalyst and begin to polymerize. During this process, a colour change of the biomorphs can be observed by the naked eye. After $3 \mathrm{~h}$ the white powder turns grey and after $6 \mathrm{~h}$ a black powder was obtained. To ensure that the polymer layer is neither growing too big nor crosslinks the structures, the incubation time was kept at $6 \mathrm{~h}$. After extracting the structures from the desiccator, the shapes of the naked biomorphs used as starting material remained nearly unchanged. Elemental analysis via energy dispersive $\mathrm{X}$-ray spectroscopy (EDX) showed $\mathrm{Ba}, \mathrm{Cu}, \mathrm{Cl}, \mathrm{C}$, $\mathrm{O}, \mathrm{N}$ and traces of $\mathrm{Si}$. Except the higher amount of $\mathrm{N}$ and the signals from the catalyst, the spectrum looks identical to an EDX of the naked biomorphs. The most meaningful proof of the full coverage and subsequent preservation of the biomorph form is the dissolution of the inner core which was achieved 
with $0.05 \mathrm{M}$ acetic acid. The core dissolves much slower compared to normal silica-biomorphs and as a result hollow structures were obtained and shown in the SEM image in Figure 3C. Note that the SEM images were recorded with a backscatter detector, which gives a good material contrast. The structures in Figure 3B show a higher contrast compared to the hollow structures without $\mathrm{BaCO}_{3}$ in C. The EDX spectrum of these polymer replicas as well as their preliminary stages are shown in Figure 3D. The black spectrum shows the silica-biomorphs, the red spectrum the naked biomorphs with $\mathrm{CuCl}_{2}$, which can be found at $8.02 \mathrm{eV}$. Here we can see that the outer silica layer has vanished and no $\mathrm{Si}$ signal was measured at $1.75 \mathrm{eV}$. In the upper blue spectrum, the Ba signals (green rectangular outline) have vanished and only traces of the raw material (Ba: 0.24 ; Si: 0.25 at.\%) and the catalyst $(0.4$ at.\%) are detected. The main component consists of carbon and nitrogen. Therefore, the pPy route is most suitable to preserve micro-sculptures on the microscale and to obtain conductive inverse biominerals.

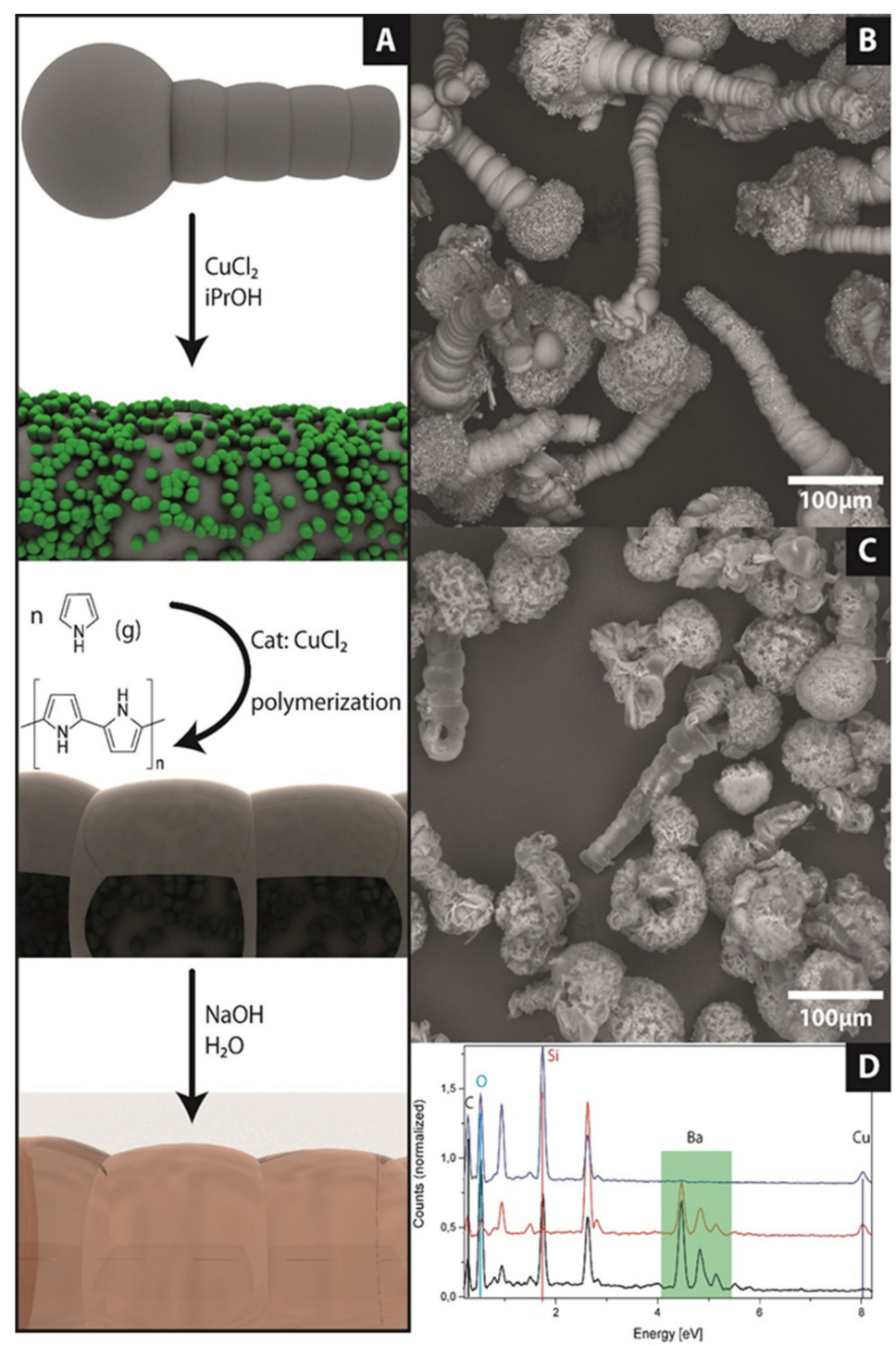

Figure 3. (A) Schematic illustration of the pPy route to preserve biomorphic structures. $\mathrm{CuCl}_{2}$ crystals are attached from $\mathrm{iPrOH}$ solution on the surface of a naked biomorph. In the next step pyrrole diffuses via the gas phase onto the surface and is polymerized by $\mathrm{CuCl}_{2}$. After the polymerization the inner parts can be removed by sodium hydroxide solution. (B) SEM image of catalyst crystals attached on biomorph worms. (C) Inverse biomorphs after Polymerization of pyrrole (Py) and removal of the inner part. (D) Energy dispersive X-ray (EDX) spectra of the different steps to plastic biomorphs. The untreated biomorphs are shown in black. Naked biomorphs with $\mathrm{CuCl}_{2}$ in red and the final inverse biomorphs without inorganics are shown in blue. 


\section{Conclusions}

We have achieved a full coverage of silica-carbonate composites by using PCDA and pyrrole to form an organic layer around the inorganic motifs. Thus, we have converted purely inorganic-inorganic composites into hybrids than can be named inverse biomorphs. The pathways to obtain these organic or hybrid structural motifs are described in detail and the methodology can be adapted to other microscopic biominerals or synthetic biomimetic architectures. Furthermore, the inorganic and structuring part of the biomorphs can be removed at ambient conditions resulting in a structured organic replica of the biomorph. With this straight-forward method, micro-structured functional materials can be formed and used as stretchable supercapacitors.

Author Contributions: J.O., M.K., H.C. and J.-M.G.-R. conceived and designed the experiments. The experiments where performed by J.O., N.U. (pPy part) and M.W. (pPCDA part). Analytical measurements where performed by J.O., N.U. and M.W., J.O. wrote the paper under supervision of J.-M.G.-R., H.C. and M.K.

Funding: The authors thank the European Research Council under the European Union's seventh Framework Program (FP7/2007-2013)/ERC grant agreement no. 340863.

Acknowledgments: The authors thank the Particle Analysis Center of the University of Konstanz (SFB 1214), the Nanostructure Laboratory and the Bioimaging center of the University of Konstanz for access to their instruments and Andra-Lisa Hoyt for corrections.

Conflicts of Interest: The authors declare no conflict of interest.

\section{References}

1. Kellermeier, M.; Colfen, H.; Garcia-Ruiz, J.M. Silica biomorphs: Complex biomimetic hybrid materials from "sand and chalk". Eur. J. Inorg. Chem. 2012, 2012, 5123-5144. [CrossRef]

2. Nakouzi, E.; Steinbock, O. Self-organization in precipitation reactions far from the equilibrium. Sci. Adv. 2016, 2, e1601144. [CrossRef]

3. Garcia-Ruiz, J.M.; Hyde, S.T.; Carnerup, A.M.; Christy, A.G.; van Kranendonk, M.J.; Welham, N.J. Self-assembled silica-carbonate structures and detection of ancient microfossils. Science 2003, 302, 1194-1197. [CrossRef] [PubMed]

4. Mann, S. The chemistry of form. Angew. Chem. Int. Ed. 2000, 39, 3392-3406. [CrossRef]

5. Addadi, L.; Weiner, S. Control and design principles in biological mineralization. Angew. Chem. Int. Ed. 1992, 31, 153-169. [CrossRef]

6. Lowenstam, H.A.; Weiner, S.; Weiner, S. On Biomineralization; Oxford University Press: New York, NY, USA, 1989; Volume 324.

7. Kellermeier, M.; Melero-García, E.; Kunz, W.; García-Ruiz, J.M. Local autocatalytic co-precipitation phenomena in self-assembled silica-carbonate materials. J. Colloid Interface Sci. 2012, 380, 1-7. [CrossRef] [PubMed]

8. Zhang, G.; Delgado-Lopez, J.M.; Choquesillo-Lazarte, D.; Garcia-Ruiz, J.M. Growth behavior of monohydrocalcite (caco3 center dot h2o) in silica-rich alkaline solution. Cryst. Growth Des. 2015, 15, 564-572. [CrossRef]

9. Zhang, G.; Garcia-Ruiz, J.M.; Sanchez-Migallon, J.M. Growth behaviour of silica/carbonate nanocrystalline composites of calcite and aragonite. J. Mater. Chem. B 2017, 5, 1658-1663. [CrossRef]

10. Zhang, G.; Verdugo-Escamilla, C.; Choquesillo-Lazarte, D.; Garcia-Ruiz, J.M. Thermal assisted self-organization of calcium carbonate. Nat. Commun. 2018, 9, 5221. [CrossRef]

11. Kellermeier, M.; Melero-Garcia, E.; Glaab, F.; Eiblmeier, J.; Kienle, L.; Rachel, R.; Kunz, W.; Garcia-Ruiz, J.M. Growth behavior and kinetics of self-assembled silica-carbonate biomorphs. Chem. Eur. J. 2012, 18, 2272-2282. [CrossRef] [PubMed]

12. García-Ruiz, J.M.; Melero-García, E.; Hyde, S.T. Morphogenesis of self-assembled nanocrystalline materials of barium carbonate and silica. Science 2009, 323, 362-365. [CrossRef] [PubMed]

13. Opel, J.; Kellermeier, M.; Sickinger, A.; Morales, J.; Cölfen, H.; García-Ruiz, J.-M. Structural transition of inorganic silica-carbonate composites towards curved lifelike morphologies. Minerals 2018, 8, 75. [CrossRef]

14. Bittarello, E.; Roberto Massaro, F.; Aquilano, D. The epitaxial role of silica groups in promoting the formation of silica/carbonate biomorphs: A first hypothesis. J. Cryst. Growth 2010, 312, 402-412. [CrossRef] 
15. Opel, J.; Hecht, M.; Rurack, K.; Eiblmeier, J.; Kunz, W.; Colfen, H.; Kellermeier, M. Probing local ph-based precipitation processes in self-assembled silica-carbonate hybrid materials. Nanoscale 2015, 7, 17434-17440. [CrossRef]

16. Montalti, M.; Zhang, G.; Genovese, D.; Morales, J.; Kellermeier, M.; García-Ruiz, J.M. Local ph oscillations witness autocatalytic self-organization of biomorphic nanostructures. Nat. Commun. 2017, 8, 14427. [CrossRef]

17. Alexander, G.B.; Heston, W.; Iler, R.K. The solubility of amorphous silica in water. J. Phys. Chem. 1954, 58, 453-455. [CrossRef]

18. Iler, K.R. The Chemistry of Silica. Solubility, Polymerization, Colloid and Surface Properties and Biochemistry of Silica; John Wiley \& Sons: Hoboken, NJ, USA, 1979.

19. Garcia Ruiz, J.M.; Carnerup, A.; Christy, A.G.; Welham, N.J.; Hyde, S.T. Morphology: An ambiguous indicator of biogenicity. Astrobiology 2002, 2, 353-369. [CrossRef] [PubMed]

20. Opel, J.; Wimmer, F.P.; Kellermeier, M.; Cölfen, H. Functionalisation of silica-carbonate biomorphs. Nanoscale Horiz. 2016, 1, 144-149. [CrossRef]

21. Pang, J.B.; Yang, L.; McCaughey, B.F.; Peng, H.S.; Ashbaugh, H.S.; Brinker, C.J.; Lu, Y.F. Thermochromatism and structural evolution of metastable polydiacetylenic crystals. J. Phys. Chem. B 2006, 110, 7221-7225. [CrossRef] [PubMed]

22. Patlolla, A.; Zunino, J.; Frenkel, A.I.; Iqbal, Z. Thermochromism in polydiacetylene-metal oxide nanocomposites. J. Mater. Chem. 2012, 22, 7028-7035. [CrossRef]

23. Göppert, A.; Cölfen, H. Infiltration of biomineral templates for nanostructured polypyrrole. Rsc. Adv. 2018, 8, 33748-33752. [CrossRef]

24. Munekawa, Y.; Oaki, Y.; Imai, H. An experimental study on the processes of hierarchical morphology replication by means of a mesocrystal: A case study of poly (3, 4-ethylenedioxythiophene). Langmuir 2014, 30, 3236-3242. [CrossRef]

25. Oaki, Y.; Kijima, M.; Imai, H. Synthesis and morphogenesis of organic polymer materials with hierarchical structures in biominerals. J. Am. Chem. Soc. 2011, 133, 8594-8599. [CrossRef]

26. Janata, J.; Josowicz, M. Conducting polymers in electronic chemical sensors. Nat. Mater. 2003, 2, 19-24. [CrossRef] [PubMed]

27. Geetha, S.; Rao, C.R.K.; Vijayan, M.; Trivedi, D.C. Biosensing and drug delivery by polypyrrole. Anal. Chim. Acta 2006, 568, 119-125. [CrossRef]

28. Unni, S.M.; Dhavale, V.M.; Pillai, V.K.; Kurungot, S. High pt utilization electrodes for polymer electrolyte membrane fuel cells by dispersing pt particles formed by a preprecipitation method on carbon "polished" with polypyrrole. J. Phys. Chem. C 2010, 114, 14654-14661. [CrossRef]

29. Olson, T.S.; Pylypenko, S.; Atanassov, P.; Asazawa, K.; Yamada, K.; Tanaka, H. Anion-exchange membrane fuel cells: Dual-site mechanism of oxygen reduction reaction in alkaline media on cobalt-polypyrrole electrocatalysts. J. Phys. Chem. C 2010, 114, 5049-5059. [CrossRef]

30. Ge, H.; Wallace, G.G. High-performance liquid chromatography on polypyrrole-modified silica. J. Chromatogr. A 1991, 588, 25-31. [CrossRef]

31. Choi, C.; Kim, J.H.; Sim, H.J.; Di, J.; Baughman, R.H.; Kim, S.J. Microscopically buckled and macroscopically coiled fibers for ultra-stretchable supercapacitors. Adv. Energy Mater. 2017, 7, 1602021. [CrossRef]

32. Siglreitmeier, M.; Wu, B.; Kollmann, T.; Neubauer, M.; Nagy, G.; Schwahn, D.; Pipich, V.; Faivre, D.; Zahn, D.; Fery, A.; et al. Multifunctional layered magnetic composites. Beilstein J. Nanotechnol. 2015, 6, 134-148. [CrossRef]

33. Oaki, Y.; Imai, H. The hierarchical architecture of nacre and its mimetic material. Angew. Chem. Int. Ed. 2005, 44, 6571-6575. [CrossRef] [PubMed]

34. Oaki, Y.; Imai, H. Nanoengineering in echinoderms: The emergence of morphology from nanobricks. Small 2006, 2, 66-70. [CrossRef] [PubMed]

35. Dei, S.; Matsumoto, A.; Matsumoto, A. Thermochromism of polydiacetylenes in the solid state and in solution by the self-organization of polymer chains containing no polar group. Macromolecules 2008, 41, 2467-2473. [CrossRef]

(C) 2019 by the authors. Licensee MDPI, Basel, Switzerland. This article is an open access article distributed under the terms and conditions of the Creative Commons Attribution (CC BY) license (http:/ / creativecommons.org/licenses/by/4.0/). 